\title{
The Academic Self-Efficacy Among Undergraduates: The Role of Gender, CGPA and Trait Emotional Intelligence
}

\author{
IFFAH ADLINA IBRAHIM, TAN KOCK WAH* \\ Faculty of Cognitive Sciences and Human Development, Universiti Malaysia Sarawak (UNIMAS), 94300 Kota \\ Samarahan, Sarawak, Malaysia \\ *Corresponding author: kwtan@unimas.my
}

\begin{abstract}
Academic self-efficacy is important for students which will help them to perform better in studies. This study aims to explore the level of academic self-efficacy among UNIMAS undergraduates based on gender, CGPA and trait emotional intelligence. The samples of study involved are 50 male and 50 female participants which consists of final year students from Faculty of Cognitive Sciences and Human Development. The academic self-efficacy of the students is measured using the questionnaire adopted from a study by Sachitra and Bandara (2017) and The Short Form (TEIQue-SF) Trait Emotional Intelligence Questionnaire is used to measure the trait emotional intelligence of the undergraduates. The result was analyzed using descriptive analysis and inferential analysis; independent samples t-test, One-Way ANOVA and Pearson's correlation. The results of the study have shown that female students have higher academic self-efficacy compared to male students. In addition, students who obtain a higher CGPA also have higher self-efficacy. There was also a small positive correlation between trait emotional intelligence and academic self-efficacy.
\end{abstract}

Keywords: academic self-efficacy, gender, CGPA, trait emotional intelligence

Copyright: This is an open access article distributed under the terms of the CC-BY-NC-SA (Creative Commons Attribution-NonCommercial-ShareAlike 4.0 International License) which permits unrestricted use, distribution, and reproduction in any medium, for non -commercial purposes, provided the original work of the author(s) is properly cited.

\section{INTRODUCTION}

Self-efficacy is often attributed to variables like self-trust or self-belief, self-esteem and self-motivation or optimism in doing something. People's trust in their own ability to achieve their objectives or goals which will influence their lives is also defined as self-efficacy. How a person feels, reflect and encourage themselves to achieve a goal is known as self-efficacy (Bandura, 1994a; b). Meanwhile, academic self-efficacy is the beliefs of an individual whether they managed to complete a specific academic task successfully or achieve a specific academic objective. In addition, emotional intelligence that can be defined as the ability to evaluate, regulate and use of emotions was found out to be linked with the academic self-efficacy including academic performance (Hen \& Goroshit, 2014).

In academic settings, self-efficacy plays major role to an individual success because it will affect their abilities and the actions that they will perform in a task. Academic self-efficacy is an individual's beliefs on how well they could accomplish an academic work or adapt with the academic performance (Sharma \& Nasa, 2014). According to Bandura (1977), academic self-efficacy is grounded in the self-efficacy theory which stated that the task's level of difficulty causes variations in academic self-efficacy. Few individuals believed that they are most effectual on challenging tasks whereas others favour easier tasks (Sharma \& Nasa, 2014). The academic self-efficacy affects learning and motivation among students. Therefore, it would be useful in the student's mental-learning efforts. Thus, different factors play different roles in improving academic self-efficacy (Satici \& Can, 2016). Family, friends, school and the influence of academic transitions are very important in shaping the effectiveness of academic-self efficacy.

According to Huang (2013), there have been an extensive research on gender differences in academic selfefficacy for the recent decades. The findings were inconsistent even though many researchers had investigated gender differences in academic self-efficacy. Therefore, the differences between male and female in their own perceived selfefficacy suggest that gender need to be taken into consideration for any effort to improve perceived self- efficacy (Chavez, Beltran, Guerrero, Enriquez, \& Reyes, 2014). This is because perceived self-efficacy is crucial in human performance, as it does not only directly affect behaviour, but it also affects important aspects such as 
goals, targets and opportunities in the social context. Additionally, students with higher academic self-efficacy and better emotional intelligence would somehow feel motivated to involve in academic activities and gain positive attitudes which would lead to success in academics environments (Salami, 2010). They tend to be more committed and motivated to their academic goals compared to students who have low self-efficacy and emotional intelligence.

University students are now facing a learning environment which requires them to have higher self-reliance, determination and better self-regulation. Unfortunately, this learning environment transforms higher education into a stressful and unemotional experience for the undergraduates (Brinkworth, McCann, Matthews, \& Nordstrom, 2008). There is extensive proof that high stress leads to unwanted results, which leads to inefficient learning and poor academic performance (Aboalshamat, Hou, \& Strodl, 2015). Self-efficacy beliefs are strongly linked to the level of achievement of an individual and ought to be particularly relevant in improving cognitive problem-solving strategies and lessen the withdrawal strategies (Sachitra \& Bandara, 2017). As indicated further, the findings have been inconsistent although there has been extensive research on gender differences in academic self-efficacy (Huang, 2013).

Furthermore, there is no strong evidence whether performing well academically improves students' emotional intelligence or whether positive self-efficacy leads to better academic performance (Macroveli \& SanchezRuiz, 2011). There are contradictions on past research and limited number of studies in these areas especially among Malaysian students. Besides, there is no research that has really focused on the relationship between gender, Cumulative Grade Point Average (CGPA) and trait emotional intelligence on academic self-efficacy. Further research is needed to bridge the gap and to better understand the relationship of gender, CGPA and trait emotional intelligence on academic self- efficacy.

\section{MATERIALS \& METHODS}

The data for the study was collected from the Faculty of Cognitive Sciences and Human Development, UNIMAS. The population in this research were the final year students consists of different programs comprising Cognitive Science, Human Resource and Counseling programs. This quantitative research used convenient sampling method with a sample size of 100 (50 female and 50 male students). Academic self-efficacy is measured by using the questionnaire adopted from a study which measure the academic self-efficacy in terms of gender and academic year experience of undergraduates by Sachitra and Bandara (2017). The Cronbach's Alpha value was 0.791 which indicates the appropriateness of the items measured (Sachitra \& Bandara, 2017). Meanwhile, trait emotional intelligence is measured by using The Short Form Trait Emotional Intelligence (TEIQue-SF) Questionnaire developed by Petrides (2009). The internal consistency score was 0.81 and test-retest reliability of the total score was 0.86 . Furthermore, TEIQue-SF's psychometric properties were found to be satisfactory and applicable which could be used to measure emotional intelligence of students (Deniz, Ozer, \& Isik, 2013).

The independent variables were gender, CGPA and trait emotional intelligence whereas the dependent variable was academic self-efficacy. In this study, there are three types of tests that will be used. The independent samples $t$-test is used to determine if there is any significant difference in academic self-efficacy of students based on gender. Meanwhile, One-Way Analysis of Variance (ANOVA) is used to determine if there is any significant difference in academic self-efficacy of students based on CGPA. Pearson's Correlation is used to determine if there is a relationship between academic self-efficacy and trait emotional intelligence of students.

\section{RESULTS \& DISCUSSION}

Table 1 shows the summary of descriptive statistics of male and female. The mean of academic self-efficacy for female students $(\mathrm{M}=3.54 ; \mathrm{SD}=0.340)$ is higher than that of male students $(\mathrm{M}=3.35 ; \mathrm{SD}=0.412)$. Based on Table 2, the $p$ value is 0.011 which is less than the significance level, thus $H_{01}$ is rejected. Therefore, there is a significant difference in academic self-efficacy of FCSHD undergraduates in terms of gender.

The results of the independent samples $t$-test showed that there was a significant difference in academic selfefficacy among undergraduates based on students' gender. Gender differences in academic self-efficacy have shown an inconsistent finding although this has been conducted extensively (Huang, 2013). Meanwhile, for this study the results show that female has higher academic self-efficacy compared to males. Thus, the findings indicated that female students show higher academic self-efficacy than male students which obtained the same results from Sachitra and Bandara (2017).

From the results obtained by this study, there are few explanations on why female students have higher academic self-efficacy than male students. In terms of their ability to write additional notes, time planning, asking friends for help or engaging in academic discussion with friends, female students were much more confident compared to male students. According to a study conducted for Malaysian students by Jelas and Dahan (2010), it has been found 
Trends in Undergraduate Research (2020) 3(1): e7-12

https://doi.org/10.33736/tur.1890.2020

$\mathrm{H}_{01}$ : There is no significant difference in academic self-efficacy of FSCHD undergraduates in terms of gender.

Table 1. Descriptive Statistics for Academic Self-Efficacy based on Gender

\begin{tabular}{lccccc}
\hline & Gender & N & Mean & Std. Deviation & Std. Error Mean \\
\hline \multirow{2}{*}{ Self-Efficacy } & Male & 50 & 3.35 & 0.412 & 0.058 \\
& Female & 50 & 3.54 & 0.340 & 0.048 \\
\hline
\end{tabular}

Table 2. Independent Samples t-test of Academic Self-Efficacy based on Gender

\begin{tabular}{|c|c|c|c|c|c|c|c|c|c|c|}
\hline & & \multicolumn{8}{|c|}{ t-test for Equality of Means } & \\
\hline & & \multicolumn{2}{|c|}{$\begin{array}{l}\text { Levene's Test } \\
\text { for Equality of } \\
\text { Variances }\end{array}$} & & & \multirow[t]{2}{*}{ Sig. (2-tailed) } & \multirow[t]{2}{*}{$\begin{array}{c}\text { Mean } \\
\text { Difference }\end{array}$} & \multirow[t]{2}{*}{$\begin{array}{l}\text { Std. Error } \\
\text { Difference }\end{array}$} & \multicolumn{2}{|c|}{$\begin{array}{l}\text { 95\% Confidence } \\
\text { Interval of the } \\
\text { Difference }\end{array}$} \\
\hline & & $\mathbf{F}$ & Sig. & $\mathbf{t}$ & df & & & & Lower & Upper \\
\hline & Equal variances assumed & 1.464 & 0.229 & -2.578 & 98 & .011 & -.195 & .076 & -.345 & -.045 \\
\hline \multicolumn{11}{|l|}{ Self- Efficacy } \\
\hline & Equal variances not assumed & & & -2.578 & 94.59 & .011 & -.195 & .076 & -.345 & -.045 \\
\hline
\end{tabular}


that females appear to perform better on cognitive tasks. Meanwhile, male students seem to be more attentive towards open-ended tasks which requires them to think critically (Jelas \& Dahan, 2010).

Table 3 shows the summary of descriptive statistics based on CGPA of students. The statistics for CGPA of the students for pointer 2.5-2.9 $(\mathrm{N}=24, \mathrm{M}=3.33, \mathrm{SD}=0.429)$, followed by pointer 3.0-3.4 $(\mathrm{N}=49, \mathrm{M}=3.41, \mathrm{SD}=0.385)$ and lastly for pointer 3.5 and above $(\mathrm{N}=27, \mathrm{M}=3.62, \mathrm{SD}=0.306)$. This suggests that the mean of students with higher CGPA is higher compared to students with lower CGPA. As shown in Table 4, there was a statistically significant difference between groups as determined by one-way ANOVA $[F(2,97)=4.218, p=0.018]$, indicated that the $p$ value is 0.018 which is less than the significance value $(\mathrm{p}<0.05)$, thus $H_{02}$ is rejected. Thus, there is significant difference in academic self-efficacy in terms of the students' CGPA.

This was supported by a study conducted by Akram and Ghazanfar (2014), which showed a significant positive relationship between self-efficacy and academic performance in terms of students' CGPA. A study conducted by Galyon, Blondin, Yaw, Nalls, \& Williams (2012) stated that the academic performance of high, medium and low CGPA was influenced by the students' self-efficacy. Thus, academic self-efficacy of students is one of the most influencing factors in CGPA. Basically, students with strong beliefs in academic self-efficacy will certainly be more interested in academic activities by setting their own goals and doing the best they can to achieve their goals.

CGPA is widely used to measure the outcome among university students that study the relationship of academic performance and the academic self-efficacy (Honicke \& Broadbent, 2016). According to Honicke and Broadbent (2016), academic self-efficacy has been linked to academic performance. Some moderating factors such as regulation of efforts, goal orientations and deep processing strategies have been identified. Other than that, as cited in Honicke and Broadbent (2016), academic self-efficacy has persistently been shown to correlate positively with academic performance despite the educational setting (Richardson et al., 2012; Robbins et al., 2004).

On the other hand, teachers or lecturers can also guide students to improve their academic self-efficacy throughout the tasks provided. Besides, some students are not very confident of their ability to score for specific courses, hence a personal sense to score for specific CGPA score might be important to motivate themselves. Thus, when students are not able to pay attention and remain focus on their studies, this will automatically lead to poor grades and low academic self-efficacy.

Ho2: There is no significant difference in academic self-efficacy of FSCHD undergraduates in terms of student's CGPA.

Table 3. Descriptive Statistics of Self-Efficacy based on CGPA

\begin{tabular}{lcccccc}
\hline & N & Mean & Std. Deviation & Std. Error & \multicolumn{2}{c}{ 95\% Confidence Interval for Mean } \\
Lower Bound & Upper Bound \\
\hline $\mathbf{2 . 5 - \mathbf { 2 . 9 }}$ & 24 & 3.33 & .429 & .088 & 3.15 & 3.51 \\
$\mathbf{3 . 0 - 3 . 4}$ & 49 & 3.41 & .385 & .055 & 3.30 & 3.52 \\
$\mathbf{> 3 . 5}$ & 27 & 3.62 & .306 & .059 & 3.50 & 3.74 \\
Total & 100 & 3.45 & .389 & .039 & 3.37 & 3.52 \\
\hline
\end{tabular}

Table 4. One-Way ANOVA Result for Academic Self-Efficacy based on CGPA

\begin{tabular}{lccccc}
\hline & Sum of Squares & df & Mean Square & F & Sig. \\
\hline Between Groups & 1.198 & 2 & .599 & 4.218 & .018 \\
Within Groups & 13.769 & 97 & .142 & & \\
Total & 14.966 & 99 & & & \\
\hline
\end{tabular}


Table 5 shows a low positive correlation between trait emotional intelligence and academic self-efficacy, which was statistically significant $(r=0.316, n=100, p=0.001)$. The $p$-value is 0.001 which is less than the significance value $(\mathrm{p}<0.05)$, thus $\mathrm{H}_{03}$ is rejected. It can be concluded that there is a positive but weak correlation between trait emotional intelligence and academic self-efficacy of the students.

The present study conducted among undergraduates showed a small positive correlation indicating that trait emotional intelligence has a minor impact on academic self-efficacy. Moreover, the construct for trait emotional intelligence will not show a strong direct association with cognitive capabilities in academic terms (Petrides, 2011). A study conducted by Parker, Summerfeldt, Hogan, and Majeski, (2004) shows a modest correlation between trait EI and academic achievement in high school and university samples. Thus, there is a possibility that trait EI effects vary through educational levels and subjects taken (Premuzic, Stumm, \& Furnham, 2011). Besides, a study among Iranian teachers conducted by Nikoopour et al., (2012) also shown a positive correlation between trait emotional intelligence and self-efficacy.

According to Salami (2010), in recent years, there was little concern about how emotional intelligence, selfefficacy or psychological well-being could predict the behaviors or attitudes of the students. Emotional intelligence and self-efficacy as well as the psychological well-being are the essential resources to improve learning, achievement in studies and the quality of education among students. Additionally, students with higher academic self-efficacy and better emotional intelligence would somehow feel motivated to be involved in academic activities and gain positive attitudes which will lead to academic success (Salami, 2010). They tend to be more committed and motivated to their academic goals compared to students who has low self-efficacy and emotional intelligence.

\section{Ho3: There is no significant relationship between trait emotional intelligence and academic self-efficacy of FCSHD undergraduates.}

Table 5. A Pearson's correlation between trait emotional intelligence and academic self-efficacy of undergraduates

\begin{tabular}{|c|r|c|c|}
\multicolumn{2}{c|}{} & TraitEI & Self-Efficacy \\
\hline \multirow{3}{*}{ TraitEI } & Pearson Correlation & 1 & $.316^{* *}$ \\
& Sig. (2-tailed) & & 0.001 \\
\cline { 2 - 2 } & $\mathrm{N}$ & 100 & 100 \\
\hline \multirow{3}{*}{ Self-Efficacy } & Pearson Correlation & $.316^{* *}$ & 1 \\
\cline { 2 - 2 } & Sig. (2-tailed) & 0.001 & \\
\cline { 2 - 2 } & $\mathrm{N}$ & 100 & 100 \\
\hline
\end{tabular}

\section{CONCLUSION}

The level of academic self-efficacy among undergraduates in other institution such as private universities may not be the same as the present study which is a public university due to some factors. Hence, future researchers should carry out this research in other institutions. Different results may be generated which further contribute to this field of research. In addition, this study also contributes to the research methodology in which the methods and instruments used in conducting this study can be used by other researchers to conduct their research. As this study is conducted using quantitative approach, it provides an opportunity for future researchers to conduct a qualitative study using openended surveys and interviews.

As a conclusion, this study attempts to measure the academic self-efficacy based on different variables which are gender, CGPA and trait emotional intelligence. Throughout this study, it is found that academic self-efficacy plays a vital role in student's academic performance as well as trait emotional intelligence. As conclusion, hopefully this study will become a good reference to people especially students, who not only intend to understand about academic self-efficacy but also getting engaged and become aware of their own academic self-efficacy which could help them to succeed in studies. 


\section{REFERENCES}

Aboalshamat, K., Hou, X.-Y., \& Strodl, E. (2015). Psychological well-being status among medicaland dental students in Makkah, Saudi Arabia: A cross-sectional study. Journal of Medical Teacher, 37, 75-81. Retrieved from https:// doi.org/ 10.3109/0142159X.2015.1006612.

Akram, B., \& Ghazanfar, L. (2014). Self-efficacy and academic performance of the students of Gujarat University, Pakistan. Academic Research International, 283-290.

Bandura, A. (1977). Self-efficacy: Toward a unifying theory of behavioral change. Psychological Review, 84, 191215.

Bandura, A. (1994a). Information on Self-efficacy. Retrieved from A Community of Scholars: http://www.uky.edu/ eushe2/Bandura/BanEncy.html.

Bandura, A. (1994b). Self-efficacy. In V.S. Ramachandran (Ed.), Encyclopedia of human behavior. (Vol 4, pp 7181). Academic Press.

Brinkworth, R., McCann, B., Matthews, C., \& Nordstrom, K. (2008). First year expectations and experiences: student and teacher perspective. Higher Education, 58, 157-173. doi:10.1007/s10734-008-9188-3.

Chavez, J. F., Beltran, F. M., Guerrero, A. C., Enriquez, M. d., \& Reyes, J. J. (2014). A gender study on college students' academic Self-efficacy. Science Journal of Education, 180-184. doi: 10.11648/j.sjedu.20140206.12.

Deniz, M. E., Ozer, E., \& Isik, E. (2013). Trait Emotional Intelligence Questionnaire-Short Form: Validity and reliability studies. Education and Science, 38(169), 407-419.

Galyon, C. E., Blondin, C. A., Yaw, J. S., Nalls, M. L., \& Williams, R. L. (2012). The relationship of academic selfefficacy to class participation and exam performance. Social Psychology of Education, 15, 233-249. doi:10.1007/ s11218-011-9175-x.

Hen, M., \& Goroshit, M. (2014). Academic Self-efficacy, emotional intelligence, GPA and academic procrastination in higher education. Eurasian Journal of Social Sciences, 1-10.

Foard, N. (2006). A short introduction to social research. UK: Sage Publications.

Honicke, T., \& Broadbent, J. (2016). The influence of academic Self-efficacy on academic performance: A systematic review. Educational Research Review, 53-84. Retrieved from http://dx.doi.org/10.1016/j.edurev.2015.11.002.

Huang, C. (2013). Gender differences in academic Self-efficacy: A meta-analysis. European Journal of Psychology of Education, 28(1), 1-35. doi:10.1007/s10212-011-0097-y.

Jelas, Z. M., \& Dahan, H. M. (2010). Gender and educational performance: The Malaysian perspective. Procedia Social and Behavioral Sciences, 7, 720-727. doi:10.1016/j.sbspro.2010.10.098.

Macroveli, S., \& Sanchez-Ruiz, M. J. (2011). Trait emotional intelligence influences on academic achievement and school behaviour. British Journal of Educational Psychology, 81(1), 112-134.

Nikoopour, J., Farsani, M. A., Tajbakhsh, M., \& Kiyaie, S. H. (2012). The relationship between Trait Emotional Intelligence and Self-efficacy among Iranian EFL teachers. Journal of Language Teaching and Research, 3(6), 1165-1174. doi:10.4304/jltr.3.6.1165-1174.

Parker, J. D. A., Summerfeldt, L. J., Hogan, M. J., \& Majeski,S. (2004). Emotional intelligence and academic success: Examining the transition from high school to university. Personality and Individual Differences, 36, 163-172

Petrides, K. V. (2009). Psychometric properties of the Trait Emotional Intelligence Questionnaire. In C. Stough, D.H. Saklofske, \& J.D.A. Parker (Eds), Assessing Emotional Intelligence: Theory, Research, and Applications. NY: Springer.

Petrides, K. V. (2011). Ability and Trait Emotional Intelligence . In T. Chamorro-Premuzic, S.v. Stumm, \& A. Furnham, The Wiley-Blackwell Handbook of Individual Differences (pp. 656-678). Blackwell Publishing Ltd.

Premuzic, T. C., Stumm, S.V., \& Furnham, A. (2011). (Eds) The Wiley-Blackwell handbook of individual differences (1st ed.). Blackwell Publishing Ltd.

Sachitra, V., \& Bandara, U. (2017). Measuring the academic Self-efficacy of undergraduates: The role of gender and academic year experience. World Academy of Science, Engineering and Technology, 11(11).

Salami, S. O. (2010). Emotional intelligence, Self-efficacy, psychological well-being and student's attitudes: Implications for quality education. European Journal of Educational Studies, 2(3), 247-257.

Satici, S. A., \& Can, G. (2016). Investigating academic Self-efficacy of university students in terms of sociodemographic variables. Universal Journal of Educational Research, 1874-1880. doi:10.13189/ujer.2016. 040817.

Sharma, H. L., \& Nasa, G. (2014). Academic Self-efficacy: A reliable predictor of educational perfomances. British Journal of Education, 2, 57-64. 